\title{
Transmittance of lithium disilicate ceramic of different thicknesses and opacities with different curing units
}

\author{
Martín García-Cuerva' ', Agustina Boaventura-Dubovik', María E. Iglesias² \\ 1. Universidad de Buenos Aires. Facultad de Odontología. Cátedra de Odontologĺa Restauradora, Buenos Aires, Argentina. \\ 2. Universidad de Buenos Aires. Facultad de Odontología, Cátedra de Materiales Dentales, Buenos Aires, Argentina
}

\begin{abstract}
The aim of this study was to evaluate the amount of radiating energy transmitted through lithium disilicate discs of different thicknesses and opacities with different curing units $(C U)$. Discshaped specimens $8 \mathrm{~mm}$ in diameter and $1.5 \mathrm{~mm}$ or $0.7 \mathrm{~mm}$ thick were designed with Zbrush ${ }^{\circledR}$ and Cura $3 D \circledR$ software, milled from HT and MO IPS e-maxCAD blocks (Ivoclar Vivadent) with Ceramill Mikro 4 (Amann Girrbach, Austria) and processed according to manufacturer instructions. Thickness was checked with a Mitutoyo (México) caliper. Four groups $(n=4)$ were formed: G1(HT/1.5 mm), G2(MO/1.5 mm), G3(HT/0.7 mm) y G4(MO/0.7 mm), and the effect of three CUs: Coltolux (ColteneWhaledent), LED.C, (Woodpecker Medical Instrument Co.Ltd) and Deepcure L(3M-ESPE) was tested Measurements were taken with a halogen and LED radiometer (Woodpecker ${ }^{\circledR}$ LM-1-Guilin Woodpecker Medical Instrument Co.Ltd) after applying the guide of each $C U$ directly on the reading window (d) and after
\end{abstract}

interposing each of the specimens. The ratio of transmitted energy was determined in each case and data was analyzed with repeated measures ANOVA and Tukey test for multiple comparisons. LED.C: d:1600 mW/cm2, G1: 0.31(0.00), G2: 0.14(0.00) G3: 0.54(0.01), G4: 0.38(0.01); Deepcure L: d:1500 mW/cm2, G1: 0.34(0.01), G2: 0.20(0,00), G3: 0.56(0.01), G4: 0.41(0.02); Coltolux: d:1275 mW/cm2, G1: 0.44(0.01), G2: 0.24(0,00), G3: $0.65(0.01), \quad$ G4: 0.47(0,00). Statistically significant differences were found among the curing units $(P<0.001)$ and for the interaction $C U$-thickness $(P<0.001)$ and $C U$-opacity $(P=0.023)$. Within the conditions of this study, the ratio of light transmitted through lithium disilicate structures is related to their thickness and opacity, and to the curing unit employed. Received: January 2021; Accepted: April 2021.

Keywords: lithium disilicate - ceramics - dental curing light.

\section{Transmitancia de cerámicas de disilicato de litio, de diferentes espesores y opacidades, con diferentes unidades de curado intrabucal}

\begin{abstract}
RESUMEN
Uno de los factores relacionados con éxito de las restauraciones y prótesis de cerámica de matriz vítrea es el logro de una fijación adhesiva para lo cual la correcta polimerización del medio de fijación es un requisito fundamental. El objetivo de este trabajo fue valorar la transmitancia de una cerámica a base de disilicato de litio de diferentes opacidades y espesores, con distintas unidades de curado. Probetas con forma de discos de $8 \mathrm{~mm}$ de diámetro y dos diferentes espesores $(1.5 \mathrm{~mm}$ y $0.7 \mathrm{~mm}$ ) fueron diseñadas con Zbrush ${ }^{\circledR}$ y Cura $3 D \AA$, maquinadas a partir de bloques HT y MO de IPS e-maxCAD (Ivoclar Vivadent) con Ceramill Mikro 4 (Amann Girrbach, Austria) y procesadas según instrucciones del fabricante. Se obtuvieron cuatro grupos $(\mathrm{n}=4)$ : G1(HT/1.5 mm), G2(MO/1.5 mm), G3(HT/0.7 mm) y G4(MO/0.7 mm), los espesores se controlaron con un calibre (Mitutoyo, México). A continuación, se registró la irradiancia con cada una de las unidades de curado (UC) Coltolux (Coltene-Whaledent) LED.C, (Woodpecker Medical Instrument Co.Ltd) y Deepcure L(3M-ESPE), aplicadas sobre la ventana de un radiómetro (Halogen and led radiometer Woodpecker ${ }^{\circledR}$ LM-1-Guilin Woodpecker Medical Instrument Co.Ltd) en forma
\end{abstract}

directa (d), y luego de interponer los diferentes especimenes y se calculó la proporción de energía transmitida en cada caso. Los datos se analizaron con ANOVA de medidas repetidas y prueba de Tukey para las comparaciones múltiples. LED.C: d:1600 mw/ cm2, HT/0,7mm: 0,54(0,01), HT/1,5mm:0,31(0); MO/0,7mm: 0,38(0,01), MO/1,5mm: 0,14(0,00); Deepcure L: d:1500 mW/ cm2, HT/0,7 mm: 0,56(0,01), HT/1,5 mm: 0,34(0,01), MO/0,7 mm: 0,41(0,02), MO/1,5 mm: 0,20(0,00); Coltolux: d:1275 mw/ cm2, HT/0,7 mm:0,65 (0,01), HT/1,5 mm:0,44(0,01), MO/0,7 mm: 0,47(0,00), MO/1,5mm: 0,24(0,00). Se encontraron diferencias estadísticamente significativas entre las diferentes unidades de curado $(P<0,001)$, y en la interacción unidades de curado-espesor $(P<0,001)$ y unidades de curado-opacidad $(P=0,023)$. La proporción de energía luminosa transmitida por una estructura de cerámica de disilicato de litio depende del espesor y opacidad de la restauración y de la unidad de curado utilizada.

Palabras clave: disilicato de litio - cerámica - unidades de curado. 


\section{INTRODUCTION}

Bonded ceramics have become the standard of care for esthetic restoration in current dentistry. According to numerous clinical studies, their advantages include excellent clinical performance, high rates of survival, near to ideal optical appearance, good biocompatibility, low thermal conductivity, chemical stability and surface smoothness ${ }^{1,2}$.

Glass matrix and polycrystalline ceramics are the two families, according to their structure and composition, which can be used to fabricate metalfree restorations. Glass matrix ceramics (GMCs) are preferred when the main goals are esthetic results and stable micro-mechanical and chemical adhesive interaction with composite resin luting materials ${ }^{3-6}$. Among GMCs lithium disilicate (LDS) based ceramics have gained popularity recently, due mainly to their versatility, with an indication range that goes from veneers to three-piece bridges in premolar areas and implant-supported single crowns $^{7,8}$. LDS restorations can be made either by traditional heat-pressing procedure or through a digital workflow and milling process (CAD-CAM). There are key differences in crystal distribution, shape and size between pressed and CAD-CAM restorations, all of which are prone to affect the transmittance of the structure ${ }^{8,9}$.

One of the most important factors related to clinical success of glass ceramics is the achievement of durable bonding between dental tissues and the restorative unit through a composite-based luting material (CBLM) of adequate mechanical properties ${ }^{10}$. To ensure effective adhesive interaction, not only surface treatments of both substrates, but also an adequate activation of the polymerization in the composite organic matrix, are key factors ${ }^{1,11-13}$. Adequate activation is relevant for both light-cured and dual-cured materials. Although dual-cured materials were developed in an attempt to ensure activation in regions difficult to reach by light, they present significantly lower degrees of conversion when not properly photoactivated ${ }^{1,14-17}$.

Several variables have been reported to affect the quality of CBLM polymerization, including specific luting material composition, adhesivecement negative interaction, and transmitted light attenuation due to scattering and absorption as light passes through the restoration ${ }^{14,18,19}$. The amount of radiant energy that is lost whilst being transmitted through a ceramic restoration" depends on ceramic composition, structure, quality and quantity of the crystalline phase, thickness, shade and porosity, among other factors ${ }^{14,17}$. This reduction results in less energy being absorbed by the initiator system of the luting composite and thus, a lower degree of conversion and lower mechanical and chemical properties, biological compatibility and bond strength $^{8}$.

Light transmittance for successful activation of composite luting materials depends not only on the characteristics of the restorative materials, but also the quality of the irradiated light. Hence, the transmittance in the $360-540 \mathrm{~nm}$ range should be considered, rather than the one occurring in the whole visible spectrum, which is more related to the concept of translucency as an optical property. Brodbelt $^{20}$ found that dental ceramics transmit two hundred times more light when scattering is taken into account (total transmission) and that transmittance also increases with higher wavelengths, as stated by Rayleigh's law. Transmittance of blue light would thus be overestimated if total spectrum transmission is considered. Lieberman et al. ${ }^{2}$ found that different ceramics transmitted higher rates of visible light than light in the blue spectra. This difference in transmittance may also be of interest when considering the different emission spectra of the curing units (CU) available. One study found that transmittance was significantly lower for CU emitting in the violet range than for others which spectrum was in the blue area ${ }^{1}$. The emission spectra vary among different $\mathrm{CU}$, for instance, typical halogen units have broad range of emission spectra, from about $390 \mathrm{~nm}$ to $500 \mathrm{~nm}$, while LED curing units, depending on their generation, may have different spectra of $440-500 \mathrm{~nm}, 420-475 \mathrm{~nm}$, or $390-415 \mathrm{~nm}$ and $430-490 \mathrm{~nm}$ in bimodal emission units ${ }^{21-23}$.

The aim of this study was to assess the transmittance of a lithium disilicate ceramic of different opacities and thicknesses with different curing units.

\section{MATERIALS AND METHODS}

Disc-shaped specimens $8 \mathrm{~mm}$ in diameter and 1.5 $\mathrm{mm}$ or $0.7 \mathrm{~mm}$ thick were designed with Zbrush ${ }^{\circledR}$ and Cura $3 \mathrm{D}^{\circledR}$ (Ultimaker) software, milled from high translucency (HT) and medium opacity (MO) IPS e-maxCAD blocks (Ivoclar Vivadent), (Fig. 1) with Ceramill Mikro 4 (Amann Girrbach, Austria) and processed according to manufacturer 


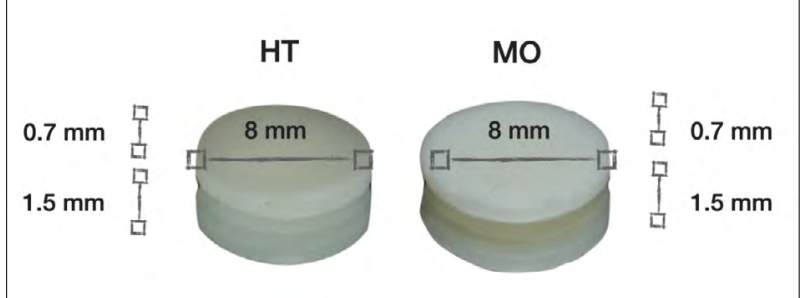

Fig. 1: Specimen dimensions and opacity

instructions. Thickness was verified in each case with a Mitutoyo (Mexico) caliper. Four different groups $(\mathrm{n}=4)$ were formed: G1(HT/1.5mm), G2(MO/1.5 $\mathrm{mm}), \mathrm{G} 3(\mathrm{HT} / 0.7 \mathrm{~mm}$ ) and $\mathrm{G} 4(\mathrm{MO} / 0.7 \mathrm{~mm})$. Three curing units with fully charged battery throughout the procedure were used: Coltolux (ColteneWhaledent) ${ }^{24}$, LED.C (Woodpecker Medical Instrument Co.Ltd) ${ }^{25}$ and Deepcure L (3M-ESPE) ${ }^{26}$ (Table 1). After installing an opaque $8 \mathrm{~mm}$ diameter ad hoc sample holder, the reading of an halogen and led radiometer (Woodpecker ${ }^{\circledR}$ LM-1-Guilin Woodpecker Medical Instrument Co.Ltd) was registered with each curing unit guide placed in the sample holder directly on the reading window (SL - source luminance) and after interposing each of the specimens (CL - ceramic luminance). Absolute values were registered and transmittance $(\mathrm{T})$ was determined in each case as the ratio between the first and second reading $\mathrm{T}=\mathrm{CL} / \mathrm{SL}$. Data was analyzed with repeated measures ANOVA and Tukey test for multiple comparisons

\section{RESULTS}

Under all the study conditions, the interposing of the specimens caused a statistically significant decrease in irradiance from $35 \%$ to $86 \%$ (Fig. 2), resulting in transmittance values of 0.65 to 0.14 , which were related to the curing unit used $(\mathrm{P}<0.001)$ and to the interactions between curing units and thickness $(\mathrm{P}<0.001)$, as well as between curing units and opacity $(\mathrm{P}=0.023)$. CU source luminance values were $1275 \mathrm{~mW} / \mathrm{cm} 2,1600 \mathrm{~mW} / \mathrm{cm} 2$ and $1500 \mathrm{~mW} /$ $\mathrm{cm} 2$ for Coltolux (Coltene-Whaledent), LED.C, (Woodpecker Medical Instrument Co.Ltd), and Deepcure L(3M-ESPE), respectively. Significant differences were also found among the three CUs studied regarding the behavior of the samples of different thicknesses and opacities (Table 2) .

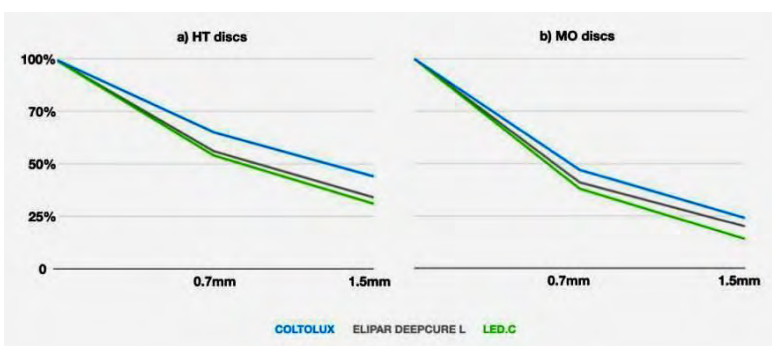

Fig. 2: a) Transmittance with HT discs. b) Transmittance with MO discs
Table 1. Manufacturer information of curing units

\begin{tabular}{|l|c|}
\hline Manufacturer & Coltolux $^{24}$ \\
\hline Diameter of guide & Coltene-Whaledent \\
\hline
\end{tabular}

Spectrum of emission 450-470 nm
LED. $C^{25}$

Woodpecker Medical Instrument Co. Ltd.

$8 \mathrm{~mm}$
Deepcure $L^{26}$

3M-ESPE

$10 \mathrm{~mm}$
$430-480 \mathrm{~nm}$

Table 2. Transmittance (Ceramic luminance/Source luminance). Mean (SD).

\begin{tabular}{|c|c|c|c|c|}
\hline Opacity & Thickness $(\mathbf{m m})$ & Coltolux & LED.C & Deepcure L \\
\hline HT & 0.7 & $0.65(0.01)$ & $0.54(0.01)$ & $0.56(0.01)$ \\
\hline \multirow{2}{*}{ MO } & 1.5 & $0.44(0.01)$ & $0.31(0.00)$ & $0.34(0.01)$ \\
& 0.7 & $0.47(0.00)$ & $0.38(0.01)$ & $0.41(0.02)$ \\
\hline
\end{tabular}

Curing unit used $(P<0.001)$, curing units-thickness $(P<0.001)$ and curing units-opacity $(P=0.023)$ 


\section{DISCUSSION}

Adhesive cementation is one of the key factors related to clinical survival and success of bonded glass ceramic restorations, as any flaw in the interface between the substrates may lead to early failure due to fracture, secondary caries, postoperative sensitivity, pigmentation and marginal leakage ${ }^{1}$. Another important aspect related to longevity is the CBLM elastic modulus, since due to the brittleness of ceramics, tensile stress is more likely to cause catastrophic failure than compressive stress, and lower values of elastic modulus in the underlying structures result in increased tensile stress ${ }^{27}$. Resinbased luting materials, whether photo-activated or dual-cure, require that enough energy is absorbed by the initiator system to reach an adequate degree of conversion, providing suitable physical, mechanical and biological properties. For that to happen, sufficient energy must be transmitted through the ceramic restorative structure ${ }^{11,28}$.

Different authors found that thickness and ceramic type were related to transmittance ${ }^{28-31}$. Zhang et al. found that $37 \%, 14 \%$ and $9 \%$ of the irradiating energy was transmitted through $1 \mathrm{~mm}, 2 \mathrm{~mm}$ and $3 \mathrm{~mm}$, respectively, of a lithium disilicate ceramic ${ }^{31}$. Furthermore, Lópes et al. ${ }^{28}$ reported transmission of $20 \%$ of total irradiated energy through $1.5 \mathrm{~mm}$ of the same material, which is consistent with the findings in the current study.

Evidence has been found that transmittance of ceramic is also dependent on the wavelength of the incident light, therefore, under equal conditions, ceramics transmit a higher fraction of energy in the $400-700 \mathrm{~nm}$ range than in the $380-540 \mathrm{~nm}$ range $^{2}$. Hardy also reported that the use of a curing unit emitting light at $390-419 \mathrm{~nm}$ resulted in a lower fraction transmitted than a CU emitting 430$510 \mathrm{~nm}$, in a zirconia-based material ${ }^{1}$. This may explain the effect of the curing unit factor found in the current study, where the higher the range emitted by the $\mathrm{CU}$, the higher the fraction of energy transmitted [Coltolux - 450-470 nm, followed by Elipar Deepcure L (3M-ESPE 430-480 nm), and subsequently by LED C Woodpecker Guilin (420$480 \mathrm{~nm})$ ]. Although the differences in emitting spectrum may seem small, they are related to significative differences in the amount of energy transmitted. O'Keefe found similar results with Vita B2 felspathic porcelain veneers, which had different transmittance at 460,470 and $480 \mathrm{~nm}^{30}$. Della Bonna et al. reported spectral behavior showing a slight linear increase in transmittance as wave length increased in most ceramics up to $550 \mathrm{~nm}$, beyond which the function is material-dependent ${ }^{29}$.

Hence, when luting an indirect ceramic restoration, successful polymerization activation is potentially compromised by two relevant factors: the wavelength of the light and the amount of energy effectively transmitted ${ }^{1,2,20}$. Regarding the latter, reductions ranging from nearly $40 \%$ to $86 \%$ of total irradiance should be expected. This could be addressed by employing a $\mathrm{CU}$ with higher irradiance to deliver sufficient energy, or by increasing curing time in order to maintain the energy dose. However, Bueno et al. found that for some luting materials, increasing curing time does not effectively compensate light attenuation due to the presence of an indirect restoration, so it should be considered material-dependent ${ }^{13}$. This could be explained by the transmitted light spectra, since the shorter the wave length, the less the transmission, so the effect should be more detrimental to CBLMs that include initiators such as PPD, TPO or Ivocerin ${ }^{\circledR}$ with absorbance peaks in the range of 350-400 $\mathrm{nm}$, than to materials with camphorquinone ${ }^{32}$.

The roughening of the inner surface of the restoration as result of acid etching, and the increase of reflection due to finishing procedures, polishing or glazing of the outer surface, could be interesting factors to add to the equation of light transmittance in dental ceramics because additional scattering and reflection, respectively, could enhance the loss of transmitted energy.

Transmission efficiency affects the degree of conversion of composite-based luting materials and has direct consequence on longevity and clinical success. Moreover, the $\mathrm{CU}$ plays an important part in this process, mainly through its emission spectrum range. Therefore, when planning the adhesive procedures for bonded ceramics, the following factors are important and should be considered: type, composition, thickness, color and translucency of the ceramic system; spectrum of emission and irradiance of the curing unit and, according to Hardy et al., the monomer fraction, the presence of TEGDMA in the resin matrix, and the initiator system of the luting material ${ }^{1}$. 


\section{DECLARATION OF CONFLICTING INTERESTS}

The authors declare no potential conflicts of interest with respect to the research, authorship, and/or publication of this article.

\section{FUNDING}

This study was supported by a grant from Universidad de Buenos Aires. UBACYT programe 20020160100037BA

\section{REFERENCES}

1. Hardy CMF, Bebelman S, Leloup G, Hadis MA et al. Investigating the limits of resin-based luting composite photopolymerization through various thicknesses of indirect restorative materials. Dent Mater. 2018;34:12781288. doi:10.1016/j.dental.2018.05.009

2. Liebermann A, Freitas Rafael C, Colle Kauling AE, Edelhoff $\mathrm{D}$ et al. Transmittance of visible and blue light through zirconia. Dent Mater J. 2018;37:812-817. doi:10.4012/ dmj.2016-287

3. Sundfeld D, Correr-Sobrinho L, Pini NI, Costa AR et al. The Effect of Hydrofluoric Acid Concentration and Heat on the Bonding to Lithium Disilicate Glass Ceramic. Braz Dent J. 2016;27:727-733. doi: 10.1590/0103-6440201601024.

4. Li R, Ma SQ, Zang CC, Zhang WY et al. Enhanced bonding strength between lithium disilicate ceramics and resin cement by multiple surface treatments after thermal cycling. PLoS One. 2019;25;14:e220466. doi: 10.1371/ journal.pone.0220466.

5. Maunula H, Hjerppe J, Lassila LLV, Närhi TO. Optical Properties and Failure Load of Thin CAD/CAM Ceramic Veneers. Eur J Prosthodont Restor Dent. 2017;25:86-92. doi: 10.1922/EJPRD_01677Maunula07.

6. Spitznagel FA, Boldt J, Gierthmuehlen PC. CAD/CAM Ceramic Restorative Materials for Natural Teeth. J Dent Res. 2018;97:1082-1091. doi: 10.1177/0022034518779759.

7. Oh S, Shin SM, Kim HJ, Paek J et al. Influence of glassbased dental ceramic type and thickness with identical shade on the light transmittance and the degree of conversion of resin cement. Int J Oral Sci. 2018;10:5. doi:10.1038/ s41368-017-0005-7

8. Jafari Z, Alaghehmand H, Samani Y, Mahdian M et al. Light transmittance of $\mathrm{CAD} / \mathrm{CAM}$ ceramics with different shades and thicknesses and microhardness of the underlying light-cured resin cement. Restor Dent Endod. 2018;43:e27. doi:10.5395/rde.2018.43.e27

9. Fabian Fonzar R, Carrabba M, Sedda M, Ferrari M et al. Flexural resistance of heat-pressed and CAD-CAM lithium disilicate with different translucencies. Dent Mater. 2017;33:63-70. doi: 10.1016/j.dental.2016.10.005.

10. Çetindemir AB, Şermet B, Öngül D. The effect of light sources and CAD/CAM monolithic blocks on degree of conversion of cement. J Adv Prosthodont. 2018;10:291299. doi: 10.4047/jap.2018.10.4.291.

11. Mendonça LM, Ramalho IS, Lima LASN, Pires LA et al. Influence of the composition and shades of ceramics on light transmission and degree of conversion of dualcured resin cements. J Appl Oral Sci. 2019;27:e20180351. doi:10.1590/1678-7757-2018-0351

\section{CORRESPONDENCE}

Dr. María Emilia Iglesias

Cátedra de Materiales Dentales

Facultad de Odontología

Universidad de Buenos Aires

Marcelo T de Alvear 2142, piso 3 B, C1122AAH

Ciudad Autónoma de Buenos Aires, Argentina

mariaemilia.iglesias@odontologia.uba.ar

12. Ilie N, Hickel R. Correlation between ceramics translucency and polymerization efficiency through ceramics. Dent Mater. 2008;24:908-914. doi:10.1016/j.dental.2007.11.006

13. Bueno AL, Arrais CA, Jorge AC, Reis AF et al. Lightactivation through indirect ceramic restorations: does the overexposure compensate for the attenuation in light intensity during resin cement polymerization? J Appl Oral Sci. 2011;19:22-27. doi:10.1590/s167877572011000100006

14. De Souza G, Braga RR, Cesar PF, Lopes GC. Correlation between clinical performance and degree of conversion of resin cements: a literature review. J Appl Oral Sci. 2015;23:358-368. doi: 10.1590/1678-775720140524.

15. Guimaraes IR, Murillo Gómez F, De Goes MF. Effect of activation mode on flexural strength and elasticity modulus of dual cure resin cements. ODOVTOS-Int. J. Dental Sc. 2016;18:61-71. DOI:10.15517/ijds.v18i1.23556

16. Mendes LC, Matos IC, Miranda MS, Benzi MR. Dual-curing adhesive resin cement: influence of the polymerization modes on the degree of conversion and microhardness. Materials Research. 2010;13:171-176.

17. Ayres AP, Andre CB, Pacheco RR, Carvalho AO et al. Indirect Restoration Thickness and Time after LightActivation Effects on Degree of Conversion of Resin Cement. Braz Dent J. 2015;26:363-367. doi:10.1590/010364402013x0024

18. Kilinc SA, Antonson PC, Hardigan A, Kesercioglu A. The Effect of Ceramic Restoration Shade and Thickness on the Polymerizationof light-and Dual-cure Resin Cements. Oper Dent. 2011;36: 661-669.

19. Ilie N, Simon A. Effect of curing mode on the micromechanical properties of dual-cured self-adhesive resin cements. Clin Oral Investig. 2012;16:505-512. doi:10.1007/ s00784-011-0527-x

20. Brodbelt RHW, O'Brien WJ, Fan PL. Translucency of Dental Porcelains J Dent Res. 1980; 59:70-75.

21. Rueggeberg FA, Giannini M, Arrais CAG, Price RBT. Light curing in dentistry and clinical implications: a literature review. Braz Oral Res. 2017;28;31(suppl 1):e61. doi: 10.1590/1807-3107BOR-2017.vol31.0061.

22. AlShaafi MM, Harlow JE, Price HL, Rueggeberg FA et al. Emission Characteristics and Effect of Battery Drain in "Budget" Curing Lights. Oper Dent. 2016;41:397-408. doi: 10.2341/14-281-L.

23. Soares CJ, Rodrigues MP, Oliveira LRS, Braga SSL et al. An Evaluation of the Light Output from 22 Contemporary Light Curing Units. Braz Dent J. 2017;28:362-371. doi: 10.1590/0103-6440201601466. 
24. https://lam.coltene.com/pim/DOC/BRO/docbro31266c-en07-20-coltolux-edsenaindv1.pdf 22/9/20

25. MANUAL 1 https://www.woodpecker.cz/Documents/ LED-C_manualEN.pdf 22/9/20

26. https://multimedia.3m.com/mws/media/1173327O/elipardeepcure-led-curing-lights-technical-product-profile.pdf

27. Liu B, Lu C, Wu Y, Zhang X et al. The effects of adhesive type and thickness on stress distribution in molars restored with all-ceramic crowns. J Prosthodont. 2011;20:35-44. doi: 10.1111/j.1532-849X.2010.00650.x.

28. Lopes C de C, Rodrigues RB, Silva AL, Simamoto Júnior $\mathrm{PC}$ et al. Degree of Conversion and Mechanical Properties of Resin Cements Cured Through Different All-Ceramic Systems. Braz Dent J. 2015;26:484-489. doi: 10.1590/01036440201300180 .
29. Della Bona A, Nogueira AD, Pecho OE. Optical properties of CAD-CAM ceramic systems. J Dent. 2014;42:12021209. doi: 10.1016/j.jdent.2014.07.005.

30. O'Keefe KL, Pease PL, Herrin HK. Variables affecting the spectral transmittance of light through porcelain veneer samples. J Prosthet Dent. 1991;66:434-438. doi: 10.1016/0022-3913(91)90501-m. PMID: 1791552.

31. Zhang X, Wang F. Hardness of resin cement cured under different thickness of lithium disilicate-based ceramic. Chin Med J (Engl). 2011;124:3762-3767.

32. Neumann MG, Schmitt CC, Ferreira GC, Corrêa IC. The initiating radical yields and the efficiency of polymerization for various dental photoinitiators excited by different light curing units. Dent Mater. 2006;22:576-584. doi: 10.1016/j. dental.2005.06.006. 